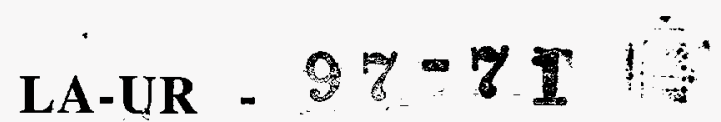

$$
\text { CONF. } 970111-4
$$

Title:

\title{
FABRICATION AND PROPERTIES OF ERBIUM
}

\author{
OXIDE
}

Author(s):

A. Neuman, M. Platero, R. Romero, K.J, McClellan, J.J.

Petrovic

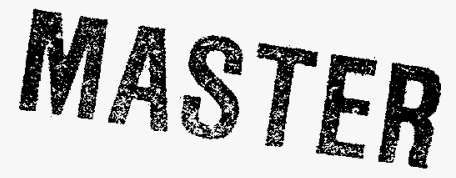

Submitted to: Acers Cocoa Beach Florida Symposium

January 12-16, 1997

DISTRIBUTION OF THIS DOCUMENT IS UNLMITED

By acceptance of this article, the publisher recognizes that the U.S. government retains a nonexclusive, royalty-free license to publish or reproduce the published form of this contribution, or to allow others to do so, for U.S. Government purposes.

The Los Alamos National Laboratory requests that the publisher identify this article as work performed under the auspices of the U.S. Department of Energy.

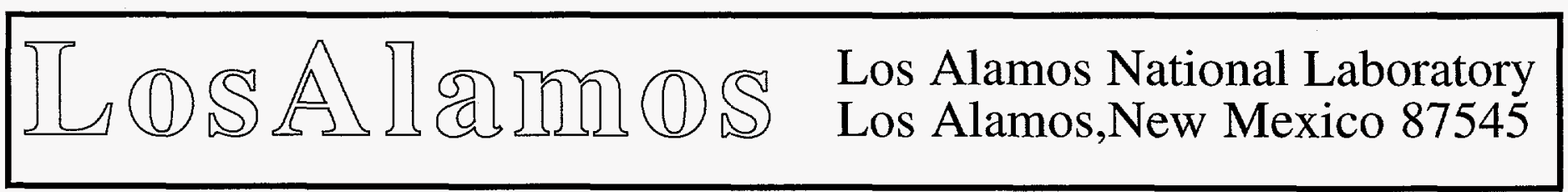




\section{DISCLAIMER}

This report was prepared as an account of work sponsored by an agency of the United States Government. Neither the United States Government nor any agency thereof, nor any of their employees, make any warranty, express or implied, or assumes any legal liability or responsibility for the accuracy, completeness, or usefulness of any information, apparatus, product, or process disclosed, or represents that its use would not infringe privately owned rights. Reference herein to any specific commercial product, process, or service by trade name, trademark, manufacturer, or otherwise does not necessarily constitute or imply its endorsement, recommendation, or favoring by the United States Government or any agency thereof. The views and opinions of authors expressed herein do not necessarily state or reflect those of the United States Government or any agency thereof. 


\section{DISCLAMMER}

Portions of this document may be illegible in electronic image products. Images are produced from the best available original document. 


\title{
CONF-970111-- of
}

\section{FABRICATION AND PROPERTIES OF ERBIUM OXIDE}

\author{
A. Neuman, M. Platero, R. Romero, K.J. McClellan and J.J. Petrovic \\ Los Alamos National Laboratory \\ MST-4 \\ Los Alamos, NM 87544
}

\begin{abstract}
Erbium oxide $\left(\operatorname{Er}_{2} \mathrm{O}_{3}\right)$ is a rare earth oxide of interest because of its chemical and thermal stability and high melting point, $2430{ }^{\circ} \mathrm{C}$. However there is relatively little information available regarding the relation between the structure and the mechanical properties of this material. A densification study of polycrystalline erbium oxide powders is reported here. Erbium oxide pellets were uniaxially pressed $(40-280 \mathrm{MPa})$ and sintered $\left(1500-1800^{\circ} \mathrm{C}\right)$ in order to obtain density data for as-received commercial powders. In addition, the particle size and distribution of as-received powders were varied by milling and the effects on densification were studied. The powders were characterized for particle size, phase and impurity content and surface area. The mechanical properties of high density sintered erbium oxide bodies were characterized using indentation hardness and toughness as a function of temperature and microstructure. Relations between the microstructure and mechanical properties are described.
\end{abstract}

\section{INTRODUCTION}

Erbium oxide is a very stable rare earth oxide of which very little is known regarding its structural properties. It is of interest because of its chemical and thermal stability at high temperatures, resistance to chemical attack, and its high melting temperature, $2430^{\circ} \mathrm{C}$. [1] Applications of interest for erbium oxide include: thermal barrier coating, oxidation resistance coating, and structural applications. The latter is of potential interest due to its large dislocation burgers vectors. A densification study, being simple and inexpensive, allows bodies of high density to be mechanically tested in order to determine their usefulness as structural materials. [2, 3]

The low temperature stable phase for erbium oxide has a body centered cubic (bcc) lattice. A high temperature hexagonal polymorph has been reported. Andreivkaya et al.[1] reported that erbium oxide undergoes a polymorphic transformation at $2320^{\circ} \mathrm{C} \pm 20^{\circ} \mathrm{C}$ due to nucleation and growth which leads to a change in crystal structure to hexagonal close packed (hcp) crystal 
structure. The erbium oxide bcc structure belongs to the Ia $\overline{3}$ space group with a lattice constant of $a=10.55 \AA$. The unit cell contains 80 atoms, where 32 erbium atoms are located on the $8 \mathrm{~b}$ and $24 \mathrm{~d}(\mathrm{u}=-0.03258)$ Wyckoff positions and the 48 oxygen atoms are on the $48 \mathrm{e}(\mathrm{x}=0.3914, \mathrm{y}=0.1528, \mathrm{z}=0.3819)$ positions. [4] The burgers vector is $1 / 2<111>$ with a magnitude of $9.09 \AA$. The closest packed planes are in the $\{110\}$ family.[5]

This study is an initial survey of erbium oxide. It involves a densification study in order to determine the best methods for attaining high densities, an etchant study in order to determine the consistency of the microstructure and the grain sizes, and initial mechanical testing results indicating its potential for future applications. There is interest in examining single crystal erbium oxide in order to understand the details of deformation characteristics. However the present study focuses on the relationship between microstructure and mechanical properties, specifically indentation hardness and toughness as a function of temperature.

\section{EXPERIMENTAL PROCEDURES}

Two erbia powders from different commercial suppliers, Advanced Materials Resources $(\mathrm{A})^{*}$ and Rhone Poulenc $(\mathrm{R})^{* *}$, were used for this study. The as-received powders were cold isostatically pressed (CIPed) in a $12.5 \mathrm{~mm}$ diameter stainless steel die at pressures varied from $80 \mathrm{MPa}$ to $280 \mathrm{MPa}$. The pellets were sintered at various temperatures in air, between $1500{ }^{\circ} \mathrm{C}$ and $1800{ }^{\circ} \mathrm{C}$ in order to show the effects of pressure and temperature on density. Density of the unfired pellets was estimated using geometric measurements, and the final density of the sintered material was measured using a water-displacement technique.[6]

In an effort to increase the density beyond that achievable with as-received powders, the powders were dry spex milled at 5 minute intervals up to 30 minutes, then for 1 hour in a tungsten jar and ball. The as-received and milled powders were characterized for phase and impurity content using powder X-ray diffraction (XRD), surface area and particle size distribution was determined using BET and a particle sizer, respectively. The powder morphology was also examined using scanning electron microscopy (SEM) as a function of milling time.

In order to reveal the grain structure of the compact, two etching methods were used; solution and thermal. The equilibrium diagram suggests that low $\mathrm{pH}$ solutions would be likely etchants.[7] Boric acid, Tartaric acid and Hydrofluoric acid solutions were used with polished sections being immersed up to 1.5 hours. Thermal etching was performed by heating 2 polished samples in a tube furnace at the temperatures, $1700^{\circ} \mathrm{C}$ and $1750^{\circ} \mathrm{C}$ for 12 hours each.

Indentation hardness and toughness of the polycrystalline compacts were measured as a function of temperature. Microhardness measurements were taken with a Nikon hot hardness tester at intervals of $200{ }^{\circ} \mathrm{C}$ from room temperature to $1400^{\circ} \mathrm{C}$. Indents were made during heat up using a Vickers indenter with a $1 \mathrm{~kg}$

\footnotetext{
*Advanced Materials Resources, Inc., Standard Life Center, 121 Kingstreet W, Suite 1740,

Toronto, Ontario, Canada M5H 3T9

${ }^{* *}$ Rhone Poulenc, Inc., One Corporate Drive, Box 881, Shelton, CT 05484
} 
load and $5 \mathrm{~s}$. dwell time, after equilibration at each temperature. Toughness was obtained by measuring the crack lengths after cool down.

\section{RESULTS AND DISCUSSION}

Sintering

Sintering results are shown in Figure 1. This figure is a plot of percent theoretical density vs. pressure which shows the variation in density between the two powders as well as the change in density with temperature. As would be expected the density increased with increasing sintering time and pressure. At the lower temperatures the Rhone Poulenc powder tended to densify better than the Advanced Materials

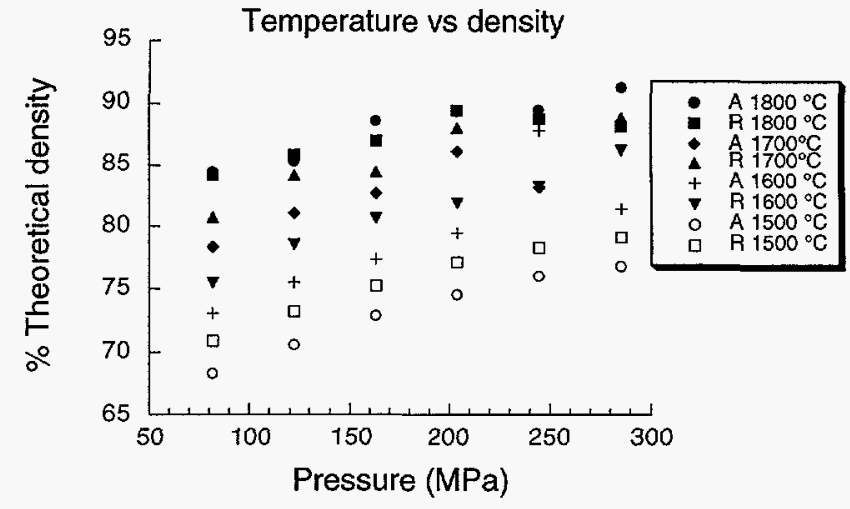

Fig. 1 Temperature and pressure vs density indicating an increase in density with increase in pressure as well as temperature.

Resources powder, but at higher temperatures these densities approached each other. Notice that the highest attained percent theoretical density was about $91 \%$. This lead to the conclusion that the powders should be milled in order to reduce the particle size and increase the density. The geometric percent theoretical density of green pellets from the milled powders indicated an increase in density of about $4 \%$ suggesting that the final sintered density should approach $95 \%$.

\section{Powder characterization}

XRD showed that both powders were cubic erbium and no impurity phases were detected. BET showed surface area of 1.3 and $1.0 \mathrm{~m}^{2} / \mathrm{g}$ for the as-received powders, 3.7 and $4.1 \mathrm{~m}^{2} / \mathrm{g}$ after milling 20 minutes, and 5.0 and $4.6 \mathrm{~m}^{2} / \mathrm{g}$ after milling for 1 hour for Advanced Materials Resources and Rhone Poulenc, respectively, indicating an increase in surface area with milling, as would be
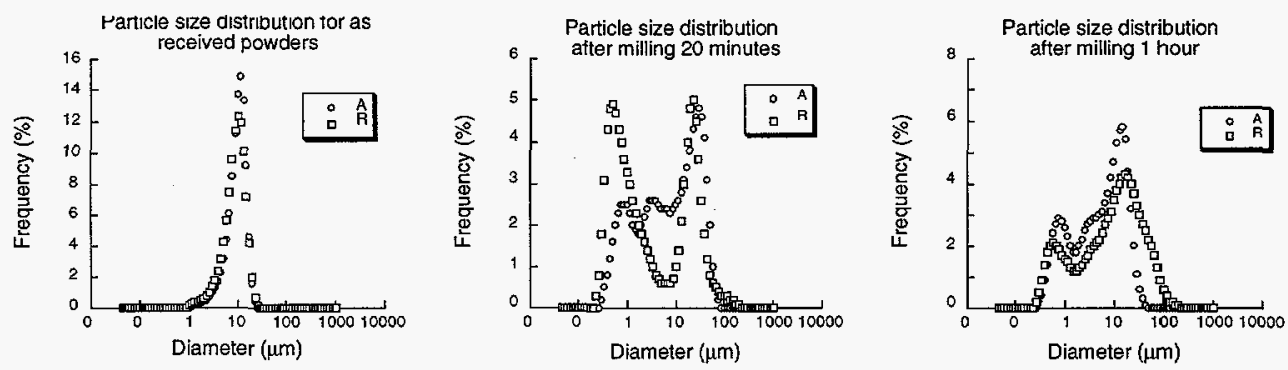

Fig. 2 Particle size distribution vs milling time. 
expected. The particle size distribution for the as-received powders ranged from 1$25 \mathrm{~mm}$ with an average particle size of about $10 \mathrm{~mm}$. As can be seen in Figure 2 after 20 minutes of milling the powders showed a bimodal and trimodal distribution for Rhone Poulenc and Advanced Materials Resources, respectively. After milling for 1 hour both powders showed trend towards a trimodal distribution.
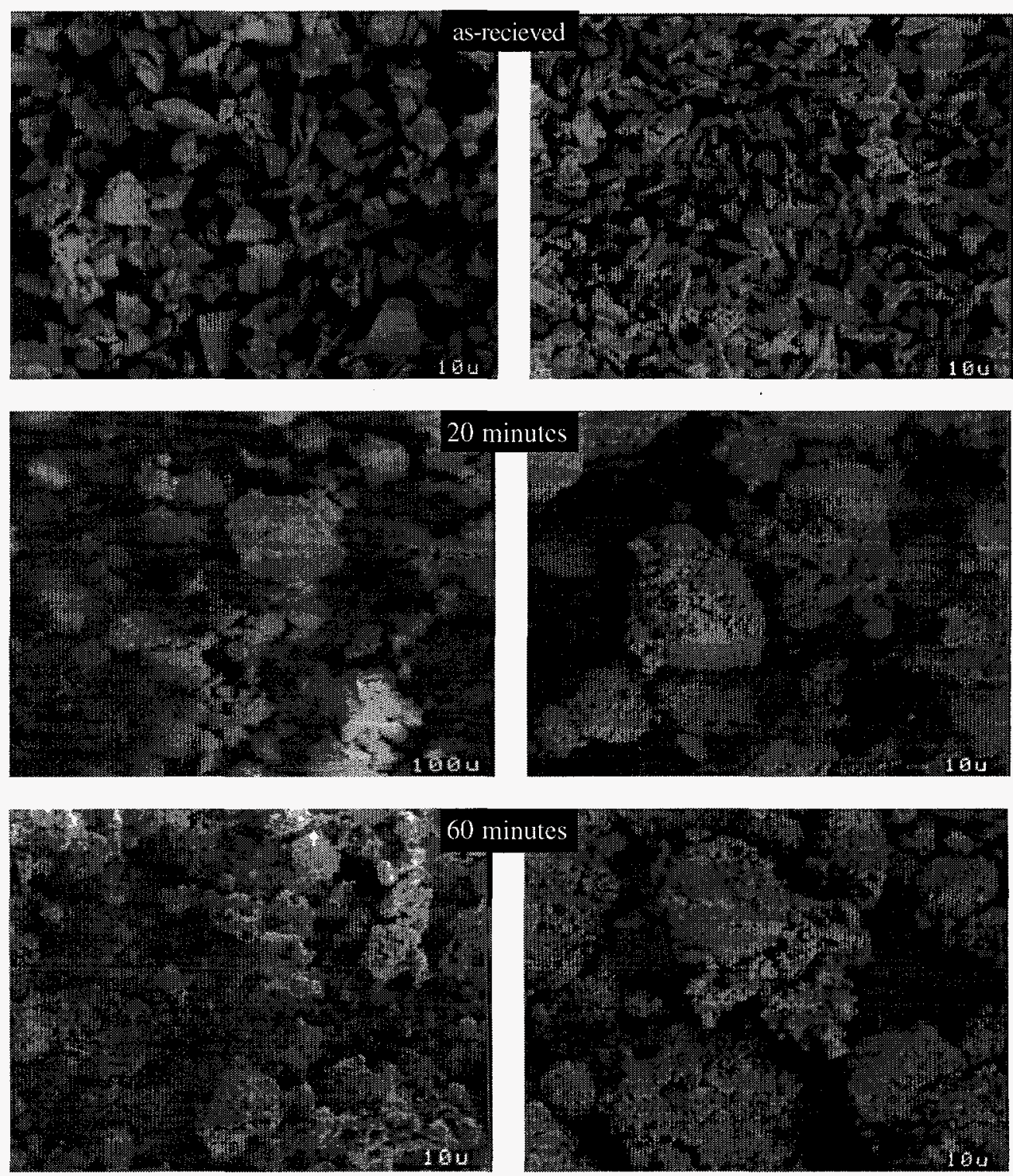

A

$\mathbf{R}$

Fig. 3 SEM of both powders: as-received, after 20 minutes of milling and after 1 hour of milling. 
Effects of milling on powder

Figure 3 is an SEM montage of the powders before and after milling. The milling times indicated are 20 minutes and 1 hour. This figure shows that before milling the powders are jagged and angular indicating low flow properties. After 20 minutes of milling the particles are smaller and agglomerate into spheres. These spheres tend to flow better and appear to be relatively soft agglomerates. After 1 hour of milling the Rhone Poulenc powder shows little or no change in appearance, whereas the Advanced Materials Resources powder changes into smaller agglomerates with reduced packing properties. Figure 2 shows the particle size distribution for all three conditions and Figure 4 shows the geometric percent theoretical density for unsintered pellets made out of these powders. The density for the Advanced Materials Resources powder decreases after 1 hour of milling

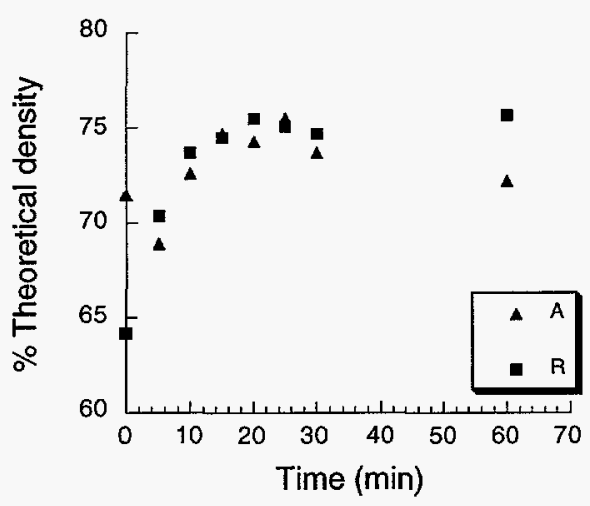

Fig. 4 Spex mill data indicating effects on green density with milling time. when compared to 20 minutes of milling, but the density for the Rhone Poulenc powder approaches a plateau or continues to increase slightly. As the two powders are milled agglomerates start to form that may show better flowability and consequently pack better. Upon subsequent milling the Rhone Poulenc powder undergoes no detrimental effects and shows continued increase in density, whereas the Advanced Materials Resources powder undergoes a decrease in agglomerate size, which causes a decrease in the density. This decrease in density may be cause by either reduced flow properties of the powder or a change in the agglomerates to a hard agglomerate that is harder to pack.

\section{Etching}

The highest density samples of as-received powders for both powders were etched in order to determine grain size and consistency of microstructure. Two methods were attempted: chemical and thermal. For the chemical etching, boric acid and tartaric acid were used at a $\mathrm{pH}$ of 4.6 and 2.0 , respectively. The samples were etched and inspected at various intervals with a cumulative time of about 1.5 hours. No grain boundary relief was observed.

Then a sample was etched with hydrofluoric acid (HF). HF did not etch the sample in the sense of showing grain boundaries, but it did clean the sample, i.e. it was more of a general polishant rather then a grain boundary etchant. In this case, over-etching displayed the scratches produced during polishing.

For thermal etching, two different temperatures were used: $1700{ }^{\circ} \mathrm{C}$ and $1750{ }^{\circ} \mathrm{C}$, both for 12 hours. Grain sizes of on average $10 \mathrm{~mm}$ were revealed (Figure 5a) with a range from $3 \mathrm{~mm}$ to $20 \mathrm{~mm}$ when etched at $1700^{\circ} \mathrm{C}$. The 1750 ${ }^{\circ} \mathrm{C}$ heat treat over-etched the sample (Figure $5 \mathrm{~b}$ ). There was a definite effect on morphology during thermal etching. The as-sintered sample had jagged pores, but 

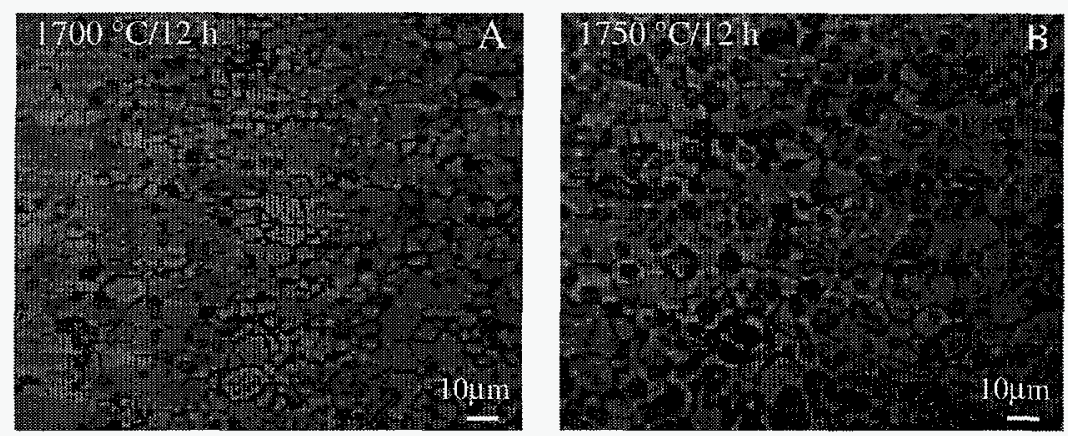

after etching at

$1700{ }^{\circ} \mathrm{C}$ for 12

hours the pores

became more

rounded and

increased

somewhat in

size. There was

evidence of

unusually large

grains, but it is

not clear yet

whether this was

due to the particle size

Resources samples sintered at $1800^{\circ} \mathrm{C}$ for 12 hours. The etch at $1700^{\circ} \mathrm{C}$ shows grain sizes of about $10 \mu \mathrm{m}$, but overetching occurred at $1750^{\circ} \mathrm{C}$.

distribution of the powder or grain growth. After etching at $1750^{\circ} \mathrm{C}$ the pore size increased even more and the grain size distribution appeared more uniform. This suggests that there is substantial grain growth at these temperatures and that the subsequent effects on microstructure must be considered for high temperature testing and applications.

\section{Mechanical Properties}

Figures 6 and 7 show the hardness and toughness values for the high density pellets $(89-91 \%$ dense) for both powders from room temperature to $1400{ }^{\circ} \mathrm{C}$ at $200{ }^{\circ} \mathrm{C}$ intervals. The analysis used for hardness and toughness determination[8] was by measuring the horizontal and vertical diameters of each indent (5-7 indents for each temperature) as well as the crack lengths initiated at the indent corners. The Vickers hardness was calculated from:

$$
\mathrm{VH}=1.854 \mathrm{P} / \mathrm{d}^{2}
$$

where $\mathrm{P}$ is the applied load of $1 \mathrm{Kg}$ and $d$ is the diameter of the indent. The toughness was calculated from the measured crack lengths using the

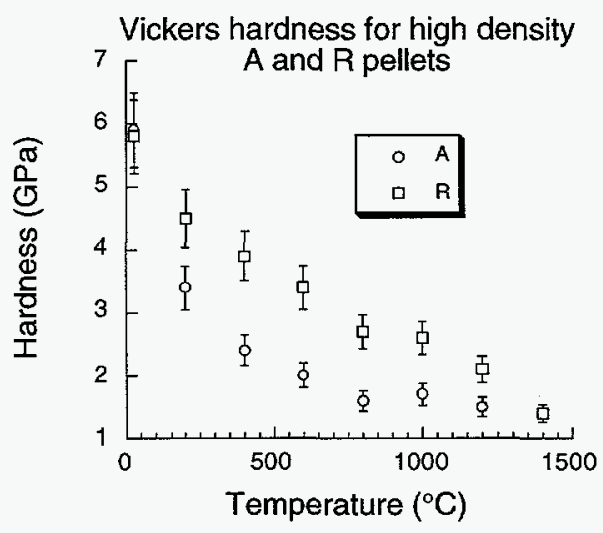

Fig. 6 Vickers hardness data for both powders showing effects of temperature on hardness. equation:

$$
\mathrm{T}=\zeta(\mathrm{E} / \mathrm{H})^{1 / 2} \mathrm{P} / \mathrm{c}^{3 / 2}
$$




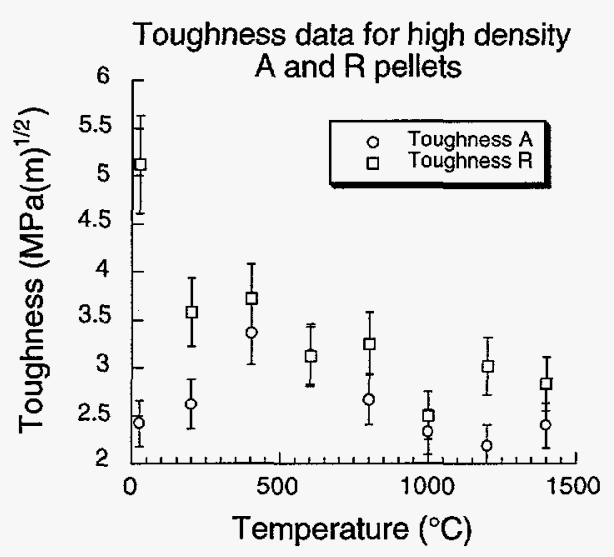

Fig. 7 Toughness data for both powders showing effects of temperature on hardness. where $\zeta=0.168, \mathrm{E}$ is the Young's modulus corrected for porosity at the various temperatures, [9] $\mathrm{H}$ is the average Vickers hardness, $P$ is the load in Newtons and $c$ is the average crack length made by the indenter.

The hardness decreases with increasing temperature from about $6 \mathrm{GPa}$ to about $1.5 \mathrm{GPa}$. The samples made with the Advanced Materials Resources powder show a decrease in hardness of $75 \%$ at about $800^{\circ} \mathrm{C}$, but the samples made with the Rhone Poulenc powder shows a more linear decrease in hardness. Temperature does not seem to affect the toughness which is on average about $3 \mathrm{MPa}(\mathrm{m})^{1 / 2}$. The toughness is comparable to reported values for ceramics such as alumina and magnesia.[5] The figures not only indicate that the Rhone Poulenc powder has a higher hardness and toughness than the Advanced Materials Resources powder but also show that the hardness for the Advanced Materials Resources powder decreases at a faster rate. Also, the difference in toughness between the two powders is rather significant at room temperature. The powder characterization of the as-received powders indicated that the powders were very similar with no detectable impurity phases. There is a difference in mechanical properties from the two powders, but the source has not been determined.

\section{CONCLUSIONS}

Sintering of as-received erbium oxide at $1800{ }^{\circ} \mathrm{C}$ provides a material about $91 \%$ dense. Substantial increase in density is achieved with $\approx 20 \mathrm{~min}$. dry spex milling. Minimal improvement or degradation is seen on longer milling. There is a difference between the powders, but the source has not been determined.

Chemical etching of erbium oxide has not proven to be beneficial in revealing microstructure, however thermal etching does reveal grain boundaries, but this heat treatment may alter microstructure. Thermal etching for shorter times should be performed in order to determine if there is exaggerated grain growth in effect.

The Rhone Poulenc powder exhibited greater hardness and toughness than the Advanced Materials Resources powder. This was somewhat surprising since the powder characterization of the as-received powders indicated that there was very little difference between them. 


\section{ACKNOWLEDGMENTS}

Funding was provided by UO/UP Los Alamos National Laboratory under a stockpile stewardship educational program. The authors would also like to thank R. Hoover, J. Bremser and J. Mitchell for technical assistance.

\section{REFERENCES}

1. E. R. Andrievskaya, L. M. Lopato and v. P. Smirnov, "The System $\mathrm{HfO}_{2}$ $\mathrm{Y}_{2} \mathrm{O}_{3}-\mathrm{Er}_{2} \mathrm{O}_{3}$ ", J. Am. Ceram. Soc. , 79[3], 714-20 (1996).

2. R. L. Coble, "Sintering Crystalline Solids. I. Intermediate and Final State Diffusion Models", J. Appl. Phys., 32[3], 787-92 (1961).

3. J. D. Hansen, R. P. Rusin, M.-H. Teng and D. L. Johnson, "Combined-Stage Sintering Model", J. Am. Ceram. Soc., 75[5], 1129-35 (1992).

4. D. Lupascu, A. Bartos, K. P. Lieb and M. Uhrmacher, "Precision PAC Measurements in $\mathrm{Er}_{2} \mathrm{O}_{3}$ and $\mathrm{Ho}_{2} \mathrm{O}_{3}$ Single Crystals and Structure Refinement", $Z$. Phys. B , 93, 441-7 (1994).

5. A. Kelly and N. H. Macmillan, Monographs on the Physics and Chemistry of Materials, Strong Solids, Third edition, (edited by F. H. Fröhlich, et al.), Clarendon Press, New York, NY (1986).

6. E. C. M. Pennings and W. Grellner, "Precise Nondestructive Determination of the Density of Porous Ceramics", J. Am. Ceram. Soc. , 72[7], 1268-70 (1989).

7. M. Pourbaix, Atlas of Electrochemical Equilibria in Aqueous Solutions, Second edition, National Association of Corrosion Engineers, Houston, TX (1974).

8. B. Lawn, Cambridge Solid State Science Series, Fracture of Brittle Solids, Second edition, (edited by E.A. Davis and F. I. M. Ward), Cambridge University Press, New York, NY (1995).

9. W. R. Manning and O. H. Jr., "Elastic Properties of Polycrystalline Yttrium Oxide, Holmium Oxide, and Erbium Oxide: High-Temperature Measurements", $J$. Am. Ceram. Soc. , 52[9], 492-6 (1969). 